University of Nebraska - Lincoln

DigitalCommons@University of Nebraska - Lincoln

Faculty Publications, UNL Libraries

Libraries at University of Nebraska-Lincoln

$1-22-2005$

Remarks on metadata management

Elaine L. Westbrooks

University of Nebraska-Lincoln, elainelw@email.unc.edu

Follow this and additional works at: https://digitalcommons.unl.edu/libraryscience

Part of the Library and Information Science Commons

Westbrooks, Elaine L., "Remarks on metadata management" (2005). Faculty Publications, UNL Libraries. 163.

https://digitalcommons.unl.edu/libraryscience/163

This Article is brought to you for free and open access by the Libraries at University of Nebraska-Lincoln at DigitalCommons@University of Nebraska - Lincoln. It has been accepted for inclusion in Faculty Publications, UNL Libraries by an authorized administrator of DigitalCommons@University of Nebraska - Lincoln. 


\title{
Remarks on metadata management
}

\author{
Elaine L. Westbrooks \\ Albert R. Mann Library, Cornell University, Ithaca, New York, USA
}

\begin{abstract}
Purpose: As digital resources proliferate, libraries plan to grant easy access to a distributed set of resources from one single entry point inside and outside the OPAC. The quest to manage the metadata about these resources becomes more important than ever. Thus, the term, "metadata management" is being used by various communities creating spatial data, enterprise applications, data warehouses, legacy environments, and bibliographic data. Unfortunately, metadata management is sparsely mentioned in the traditional information technology journals, grey literature, information technology company web sites, and the library science literature. The purpose of this viewpoint is to examine the limited use of the term metadata management in the library community and to introduce a new definition of it.

Design/methodology/approach: This viewpoint examines the limited use of the term metadata management in the library community and introduces a new definition of it.

Findings: Although the proposed definition captures the activities that libraries should be engaged as they provide access to millions of resources, this definition should constantly be examined as new technologies emerge, personnel change, and financial resources diminish.

Originality/value: The author's definition is a good start; however, to get to the complete definition of metadata management, a more comprehensive look at the workflow and procedures that exist in libraries for managing metadata is necessary.
\end{abstract}

Keywords: data analysis, library automation, archives management, digital libraries

As digital resources proliferate, libraries plan to grant easy access to a distributed set of resources (indexes, print books, digital collections, e-books, and online databases) from one single entry point that is found inside and outside the OPAC. The quest to manage the metadata about these resources becomes more important than ever. "Metadata management" is being used by various communities creating spatial data, enterprise applications, data warehouses, legacy environments, and bibliographic data. Unfortunately, metadata management is sparsely mentioned in the traditional information technology journals, grey literature, information technology company web sites, and the library science literature. This viewpoint examines the limited use of the term metadata management in the library community and introduces a new definition of it.

The first use of the term in a library context can be traced back to a 1997 Conference, Metadata-what is it? (UKOLN, 1997) The conference was organized and hosted by UKOLN, a center at the University of Bath, which provides expertise in digital information management and advice and services to the library, information, education and 
cultural heritage communities in the UK. Unfortunately, no definition of the term was included. The term metadata management enjoys an equally long history within the geospatial community, but it is associated more with the tools or software designed to manage geospatial metadata and data. ${ }^{1}$ Let us take a look at the way a few librarians have used the term metadata management.

Diane Hillmann, metadata coordinator for the National Science Digital Library (NSDL) provides a brief definition that implies that management entails documentation of processes as well as discussion. Hillmann's definition is implicit and brief, but she explicitly states, "metadata management is less a "technical" process than an "organizational" one.

The worldwide library cooperative, OCLC mentions metadata management in its web page devoted to the Metadata Switch Project, an umbrella activity for a set of projects which is constructing experimental modular services that add value to metadata. ${ }^{2}$ Metadata management is not defined but its meaning is certainly implied by its suite of web services (metadata harvesting and schema transformation) offered by OCLC in order to help institutions manage metadata.

In "Distributing and synchronizing heterogeneous metadata in geospatial information repositories for access," I propose the following definition of metadata management:

In a broad sense . . . metadata management implies the implementation of a metadata policy (i.e. principles that form the guiding framework within which metadata exists) and adherence to metadata standards. Furthermore, metadata management is the process of acquiring and maintaining a controlled set of metadata with or without automation in order to describe, discover, preserve, retrieve, and access the data to which it refers (Westbrooks, 2004). Metadata management can ensure efficiency, interoperability, extensibility, and cost-effectiveness through a clear and concise plan.

Although this definition is the result of my experiences with geospatial data, it certainly applies to the more traditional environments that deal with MARC and commonly used standards such as TEI and EAD.

By far, the most extensive definition and discussion of the term can be found in the article, "Repurposing MARC metadata: using digital project experience to develop a metadata management design." To begin, authors Kurth, Ruddy, and Rupp define metadata management as "coordinating the intellectual activity and physical resources required to create and manipulate metadata" (Kurth et al., 2004). In addition to this definition, the authors go on to say that the lack of metadata management can lead to problems, and they maintain that the first step in a coordinated approach to library metadata management is managing MARC metadata and its repurposing operations.

Each of these definitions touch on key components of what metadata management can be. However, if one is to put forth a definition of what metadata management should be, then all of these definitions miss the mark. Perhaps we should continue the discussion skillfully articulated by Kurth, Ruddy, and Rupp but also incorporate key terms and points documented in the aforementioned definitions to a more prescribed definition:

Metadata management is the sum of activities designed to create, preserve, describe, maintain access, and manipulate metadata, MARC and otherwise, that may be owned, aggregated, or distributed by the managing institution. These organizational and intellectual activities require the physical resources (web services, scripts and cross-walks), financial commitment (much like that already invested into OPACs), and policy planning that codifies the guiding framework within which metadata exists. 
The author would like to see a change in the way that technical services librarians, information technology specialists, and library administrators think about how metadata is managed today. Although this definition should capture the activities that libraries should be engaged in as they provide access to millions of resources, this definition should constantly be examined as new technologies emerge, personnel change, financial resources change, and so on. In addition, this newly formed definition can provide a point that libraries can begin to discuss management activities much in the way that they discuss collection management, preservation, or digital preservation policies.

\section{Notes}

1. See homepage for SMMS, the Spatial Metadata Management System: http://imgs.intergraph. com/smms/

2. OCLC Metadata Switch [Online]: http://www.oclc.org/research/projects/mswitch/

\section{References}

Kurth, M., Ruddy, D., Rupp, N. (2004), “Repurposing MARC metadata: using digital project experience to develop a metadata management design," Library Hi Tech 20:2, pp. 153-65.

UKOLN (1997), "Metadata: what is it?", paper presented at the UKOLN Conference, Church House Conference Centre, London, June 18, 1997. http://www.anu.edu.au/caul/mirror/metadata/ programme.html

Westbrooks, E.L. (2004), “Distributing and synchronizing heterogeneous metadata in geospatial information repositories for access," in D. Hillmann and E. L. Westbrooks, eds., Metadata in Practice, ALA, Chicago, IL . 